\title{
Ignition Failure Mode Radiochemical Diagnostics Initial Assessment
}

R. Fortner, L. Bernstein, C. Cerjan, S. W. Haan, R. Harding, S. Hatchett, R. Hoffman, J. Koch, K. Moody, D. Schneider, M. Stoyer, C. Werner, G. Zimmerman

April 23, 2007 
This document was prepared as an account of work sponsored by an agency of the United States Government. Neither the United States Government nor the University of California nor any of their employees, makes any warranty, express or implied, or assumes any legal liability or responsibility for the accuracy, completeness, or usefulness of any information, apparatus, product, or process disclosed, or represents that its use would not infringe privately owned rights. Reference herein to any specific commercial product, process, or service by trade name, trademark, manufacturer, or otherwise, does not necessarily constitute or imply its endorsement, recommendation, or favoring by the United States Government or the University of California. The views and opinions of authors expressed herein do not necessarily state or reflect those of the United States Government or the University of California, and shall not be used for advertising or product endorsement purposes.

This work was performed under the auspices of the U.S. Department of Energy by University of California, Lawrence Livermore National Laboratory under Contract W-7405-Eng-48. 


\title{
Ignition Failure Mode Radiochemical Diagnostics \\ Initial Assessment \\ April 20, 2007
}

\author{
Richard Fortner, Lee Bernstein, Charles Cerjan, Steve Haan, Rollin Harding, Steve \\ Hatchett, Rob Hoffman, Jeff Koch, Ken Moody, Dieter Schneider, Mark Stoyer, Chris \\ Werner, and George Zimmerman.
}

\section{Summary}

Radiochemical diagnostic signatures are well known to be effective indicators of nuclear ignition and burn reaction conditions. Nuclear activation is already a reliable technique to measure yield. More comprehensively, though, important quantities such as fuel areal density and ion temperature might be separately and more precisely monitored by a judicious choice of select nuclear reactions. This report details an initial assessment of this approach to diagnosing ignition failures on point-design cryogenic National Ignition Campaign targets. Using newly generated nuclear reaction cross section data for Scandium and Iridium, modest uniform doping of the innermost ablator region provides clearly observable reaction product differences between robust burn and failure for either element. Both equatorial and polar tracer loading yield observable, but indistinguishable, signatures for either choice of element for the preliminary cases studied.

\section{Background}

Ignition diagnostics are an integral, essential component of the National Ignition Facility. An effective suite of diagnostics will be required to provide information relevant to correcting implosion failures and to optimizing performance once burning conditions are achieved. Although several neutron and x-ray diagnostics will be fielded, it appears that no single diagnostic signature exists that will clearly establish a failure mode. Instead, the correlation of separate experimental data will be necessary to clearly distinguish among the various failure modes.

In this context, radiochemical diagnostics might offer valuable complementary information. For example, either the naturally occurring impurities in the ablation shell or intentional introduction of a low atomic fraction of tracer materials could provide activated materials that produce a snapshot of the imploding fuel areal density or ion temperature. Nuclear reactions would be naturally limited to the time of peak burn and thus would provide a timed implosion signal without recourse to an external time fiducial. Similarly, uniform tracer material in the ablation shell could provide angular information without fielding experiments with multiple lines of sight to the target since asymmetric burn conditions would be inherently imprinted along different angles. Physical phenomena critical to burn conditions, such as charged particle deposition lengths, would have distinctive nuclear reaction signatures also, providing data that is quite difficult to obtain otherwise. 


\section{Methodology}

Capsule Simulations

The ignition point-design target was chosen as the obvious reference choice for these simulations. This capsule includes a Copper-doped Beryllium ablator with a DT ice layer and DT gas fill. It should be noted that this design is robust with respect to the current fabrication specifications that permit low levels of various expected contaminating species. Since one of the more likely two-dimensional failure modes for this design is laser drive asymmetry, this specific failure mode was investigated. In particular, a negative Legendre mode $6\left(\mathrm{P}_{6}\right)$ contribution of $1.1 \%$ was deliberately imposed upon the ideal drive to obtain a yield of $1 \mathrm{MJ}$. A hard failure for this mode is then conventionally defined as another multiplicative factor of 1.5 to the imposed asymmetry. Post-processing these simulations for the hard failure produces the timeintegrated images plotted in Figures 1, 2 and 3 for the primary (12-17 MeV), secondary $(6-10 \mathrm{MeV})$ and tertiary $(\mathrm{E}>22 \mathrm{MeV})$ neutron signals.

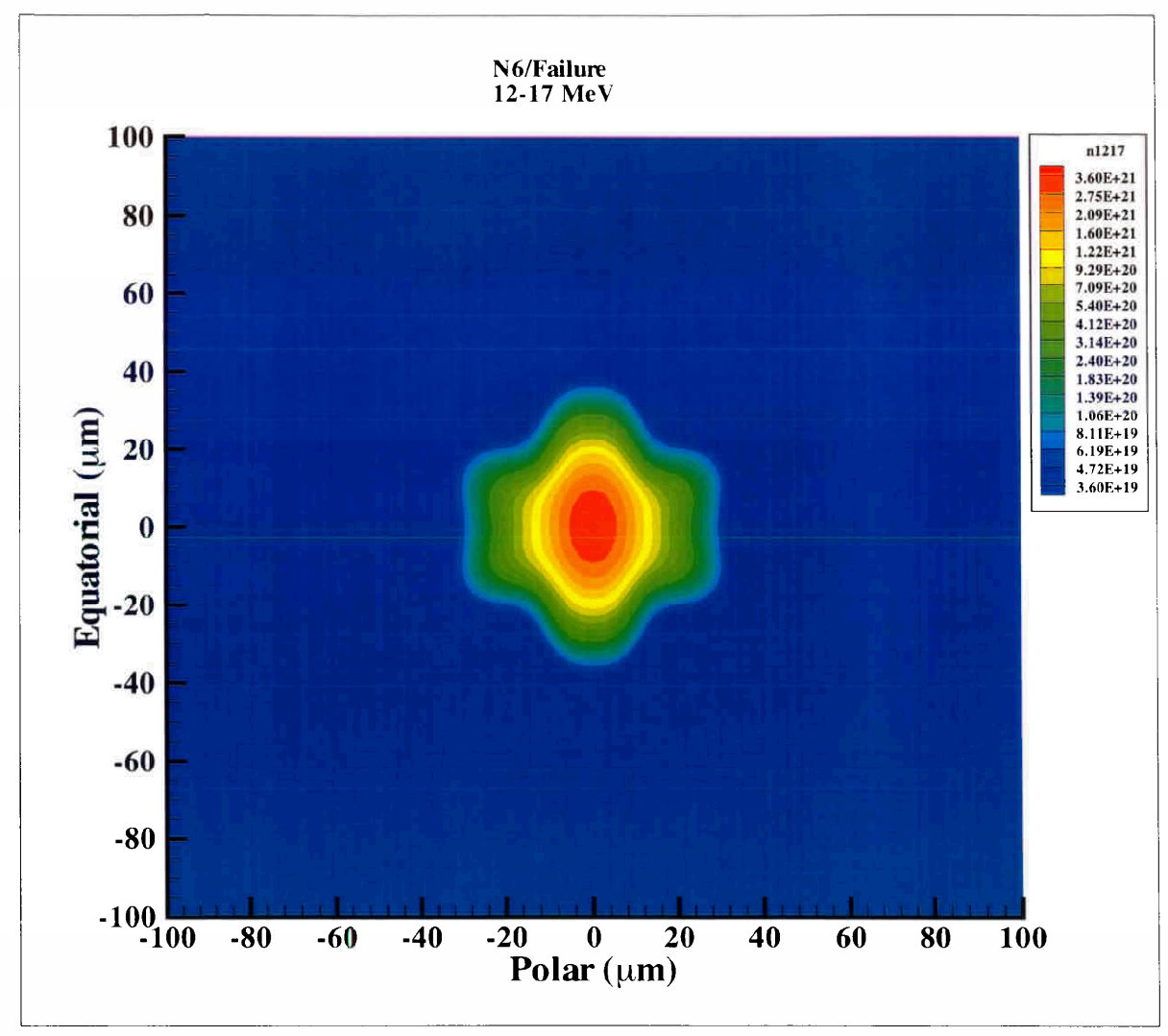


Figure 1. Time-integrated primary neutron image plotted as a function of polar and equatorial radial distance.

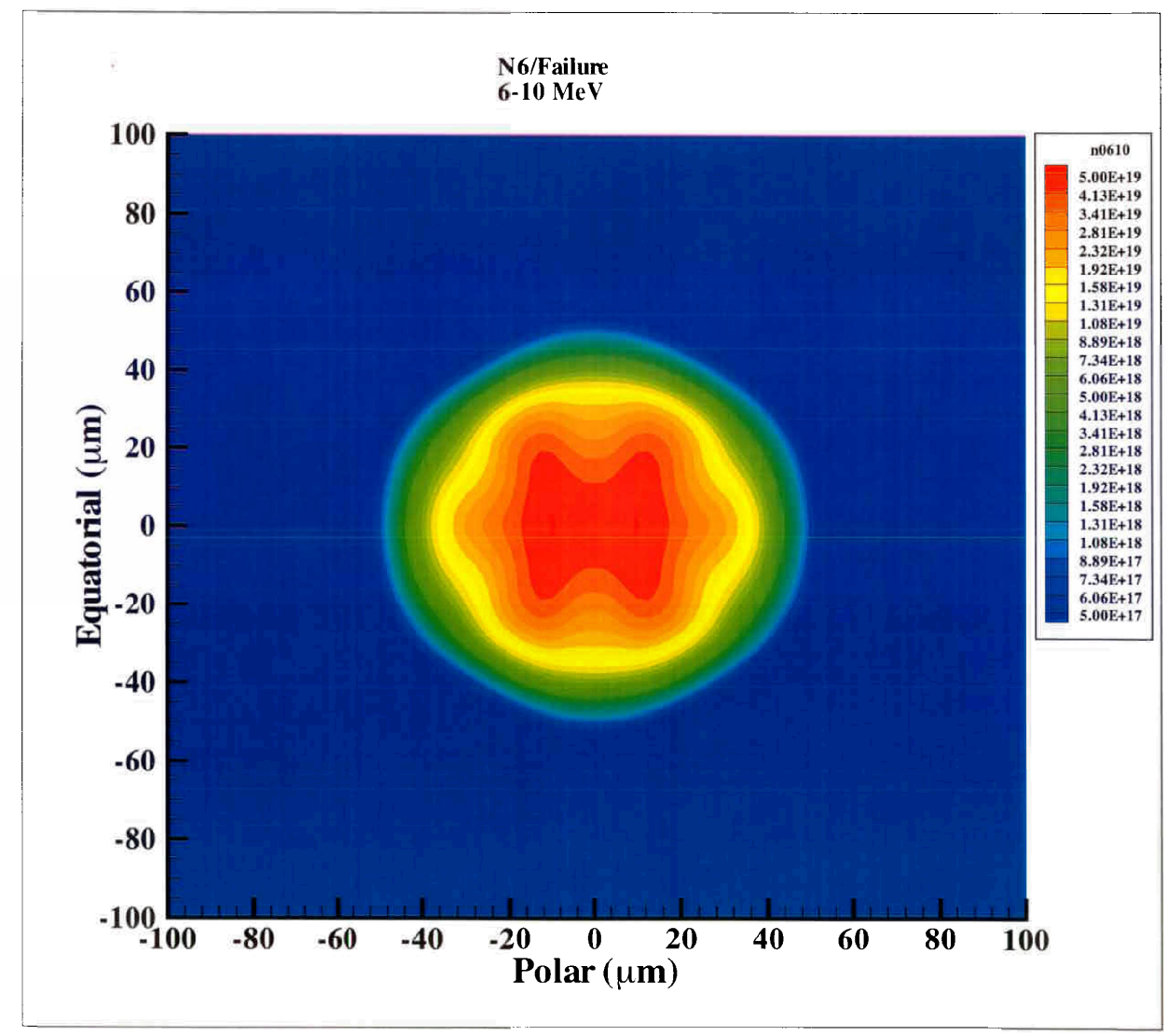

Figure 2. Time-integrated secondary (energy down-scattered) neutron image plotted as a function of polar and equatorial radial distance.

Uniform doping of the innermost ablation shell with either Scandium or Iridium was then introduced with the atomic fraction varied until no degradation of the $1 \mathrm{MJ}$ yield was observed. The corresponding hard failure simulation was obtained by applying the usual 1.5 scaling factor. In all cases, the introduction of the tracer material did not substantively alter the performance of the capsule as monitored by the usual suite of neutron and x-ray diagnostics. 


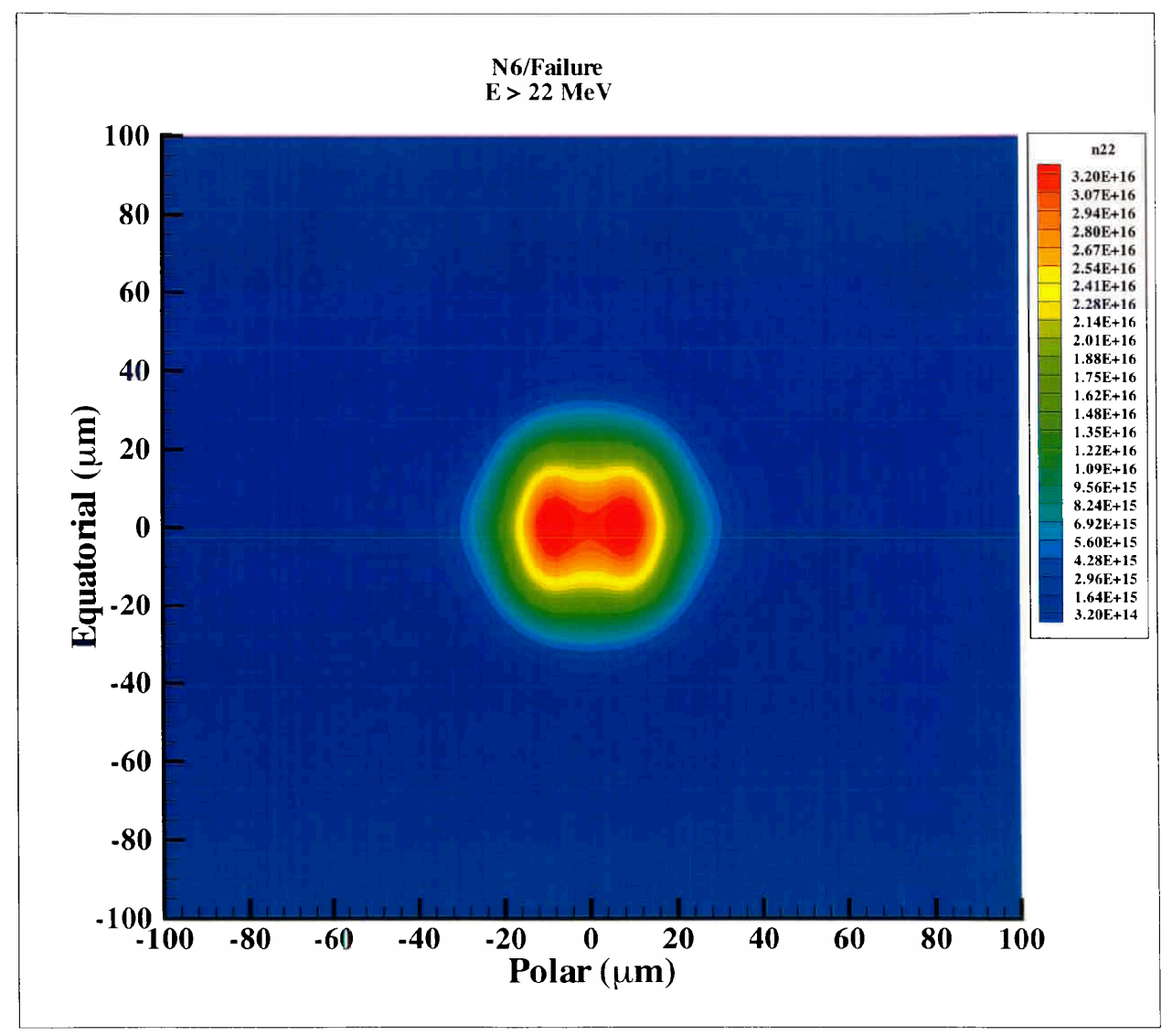

Figure 3. Time-integrated tertiary (energy up-scattered) neutron image plotted as a function of polar and equatorial radial distance.

\section{Nuclear Cross Section Data}

Two new nuclear reaction cross-section databases were developed for the loaded detector elements of scandium and iridium. All cross-sections were extended in incident particle energy to account for energetically possible up-scattered neutron events, such as those in the tertiary 22-30 MeV energy regime. This expanded energy scale required that the entire suite of standard post-processing techniques also had to be modified to accommodate this scale.

The scandium set is an extension of work published in UCRL-TR-211668 and includes both neutron and charged particle induced reactions involving $n, p, d$, and $\alpha-$ particles on all isotopes of the elements $\mathrm{K}, \mathrm{Ca}$, Sc, and $\mathrm{Ti}$ with $20<\mathrm{N}<28$, and including specific reactions linking the ground and long-lived meta-stable states of each species. This allowed production of neutron activated products as well as charged particle products that could provide mix signatures. All simulations assumed loading of natural ${ }^{45}$ Sc. Figure 4 shows the activation cross sections (b) vs. incident particle energy $(\mathrm{MeV})$. 


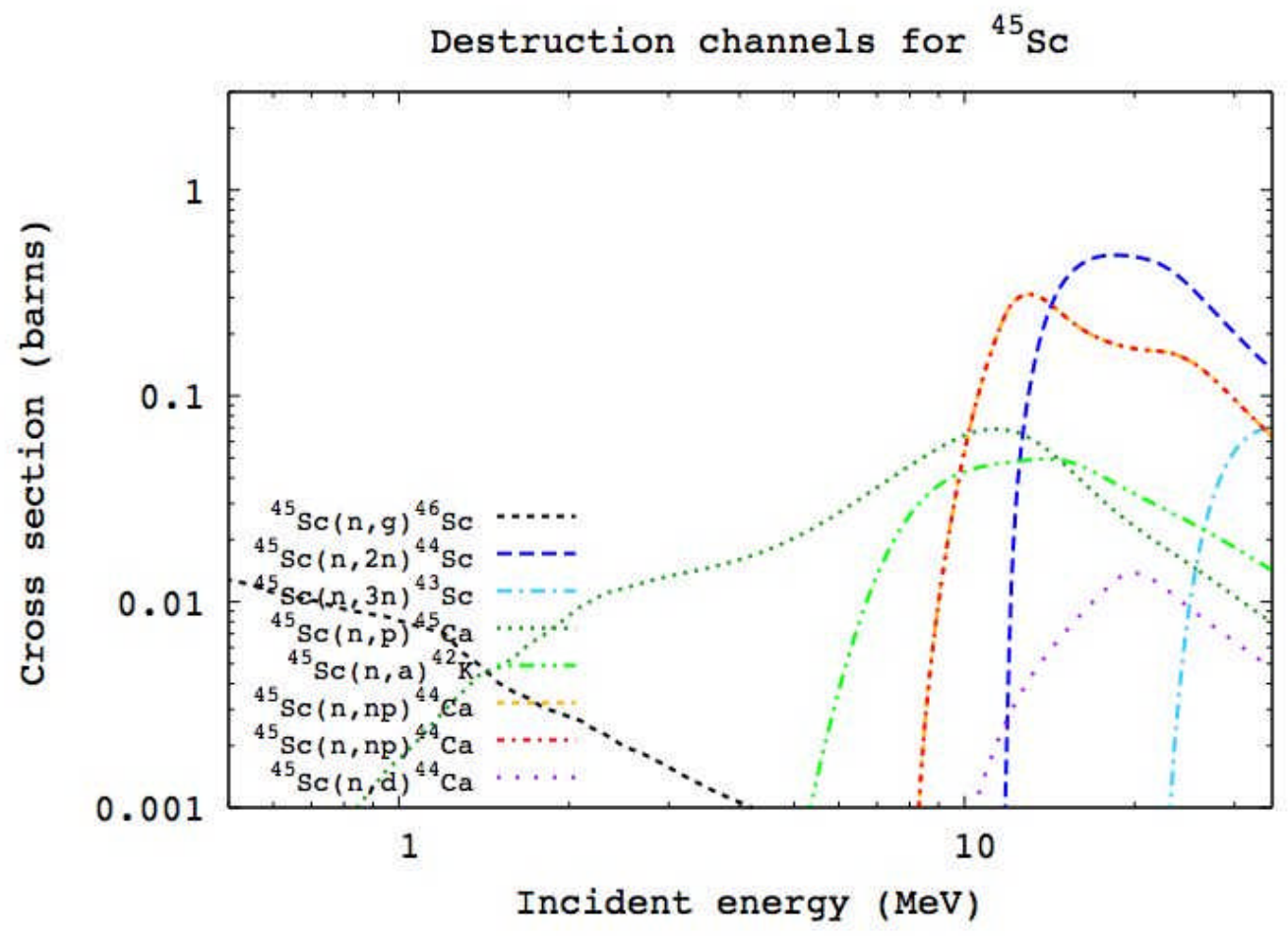

Figure 4. The activation cross-sections (all isomeric states assumed to decay to the ground state) in barns $v s$. incident neutron energy $(\mathrm{MeV})$ for the modeled neutron induced reactions on the loaded detector ${ }^{45} \mathrm{Sc}$.

The iridium set is an extension of unpublished work and includes only neutron induced reactions $(n, 3 n),(n, 2 n),(n, n),(n, p)$, and $(n, \gamma)$ on ground and isomeric states of Ir with $187<\mathrm{A}<195$. Although not mono-isotopic, iridium isotopes exhibit much lower $(\mathrm{n}, 2 \mathrm{n})$ and $(\mathrm{n}, 3 \mathrm{n})$ reaction thresholds ( 8 and 13 for $\operatorname{Ir} v s .11$ and $22 \mathrm{MeV}$ for Sc), and the peak $(\mathrm{n}, \mathrm{xn})$ cross section magnitudes also differ ( 2 vs. 0.5 barns for Ir and Sc respectively). Also, the low energy $(\mathrm{n}, \gamma)$ cross sections of Ir are larger than $\mathrm{Sc}(0.1 \mathrm{vs}$. 0.01 barns at $50 \mathrm{keV}$ respectively). Sc also exhibits a response to intermediate energy neutrons through its large (n,p) cross section (dominant between 1 and $10 \mathrm{MeV}$ ) that Ir does not. Thus, each detector set provides unique radiochemical signatures over different regimes of incident neutron energy. Also, because Ir has a much higher proton number ( 77 for Ir vs. 21 for Sc), charged particle reactions involving Ir are negligible both in the incident and exit channels, due to the higher Coulomb barrier. Figure 5 shows the activation cross sections on ${ }^{191} \mathrm{Ir}$, which are nearly identical to those on ${ }^{193} \mathrm{Ir}$. 


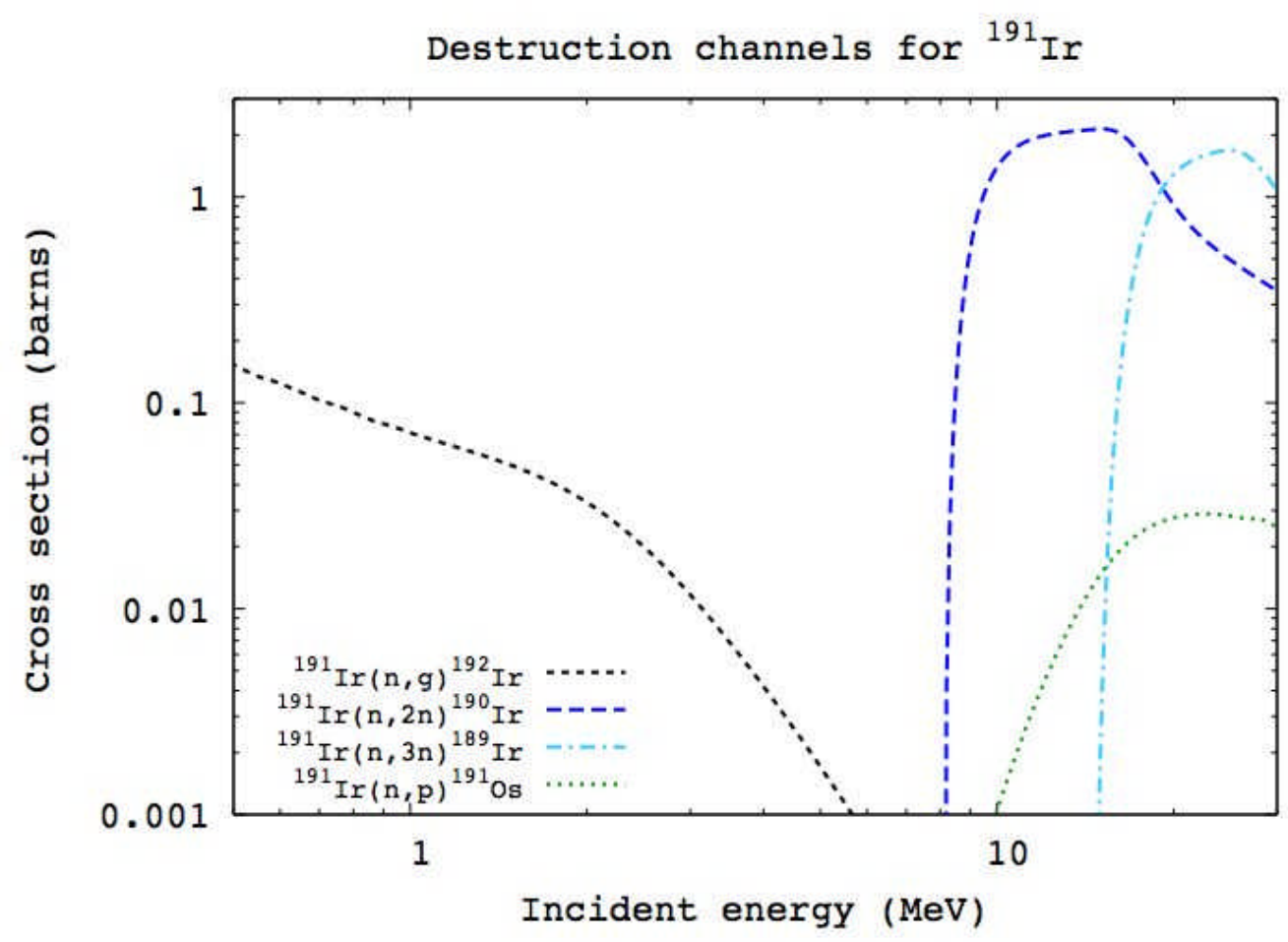

Figure 4. The activation cross-sections (all isomeric states assumed to decay to the ground state) in barns $v s$. incident neutron energy (MeV) for the modeled neutron induced reactions on the loaded detector ${ }^{191} \mathrm{Ir}$.

\section{Results}

Application of the extended data sets to capsules uniformly doped with natural scandium and iridium revealed robust, observable radiochemical signals as detailed in Tables 1 and 2 respectively. More specifically, the number of atoms for both the $1 \mathrm{MJ}$ and hard failure cases are displayed as a function of isotope with the resulting signal normalized by yield. For example, the signal (Column 6 from Tables 1 and 2 below) is given by the equation

$$
\text { Signal }=S_{R} \equiv A B S\left(1-\frac{N_{\text {low }}^{\text {products }} / Y_{\text {low }}}{N_{\text {high }}^{\text {products }} / Y_{\text {high }}}\right),
$$

where $N$ is the number of product nuclei formed and $Y$ is the total number of $14 \mathrm{MeV}$ neutrons produced in the shots. The quantity $S_{R}$ reflects how sensitively a given product nucleus distinguishes between the enhanced negative $\mathrm{P}_{6}$ asymmetry that results in the low yield "failure" and the high yield "successful" shot for a given reaction. 
Table 1

Reaction signal for loaded ${ }^{45} \mathrm{Sc}$.

$\begin{array}{ccccccc}\text { Isotope } & 1 \mathrm{MJ} & 50 \mathrm{~kJ} & 50 \mathrm{~kJ} / 1 \mathrm{MJ} & \text { atoms/yield } & \begin{array}{c}\text { Signal } \\ \mathrm{kJ} / \mathrm{MNA}\end{array} \\ { }^{45} \mathrm{Sc} & 5.00 \mathrm{E}+14 & 5.00 \mathrm{E}+14 & 1.00 \mathrm{E}+00 & 1.86 \mathrm{E}+01 & 1759.49 \% & - \\ { }^{46} \mathrm{Sc} & 6.05 \mathrm{E}+08 & 7.55 \mathrm{E}+07 & 1.25 \mathrm{E}-01 & 2.32 \mathrm{E}+00 & 131.82 \% & 1.89 \mathrm{E}+00 \\ { }^{43} \mathrm{Ca} & 6.30 \mathrm{E}+07 & 1.95 \mathrm{E}+05 & 3.10 \mathrm{E}-03 & 5.75 \mathrm{E}-02 & 94.25 \% & \\ { }^{41} \mathrm{~K} & 5.15 \mathrm{E}+06 & 1.70 \mathrm{E}+04 & 3.30 \mathrm{E}-03 & 6.13 \mathrm{E}-02 & 93.87 \% & \\ { }^{43} \mathrm{Sc} & 6.95 \mathrm{E}+06 & 2.61 \mathrm{E}+04 & 3.75 \mathrm{E}-03 & 6.96 \mathrm{E}-02 & 93.04 \% & 8.68 \mathrm{E}-03 \\ { }^{45} \mathrm{Ti} & 1.20 \mathrm{E}+08 & 2.53 \mathrm{E}+06 & 2.11 \mathrm{E}-02 & 3.92 \mathrm{E}-01 & 60.84 \% & 3.37 \mathrm{E}-03 \\ { }^{46} \mathrm{Ti} & 4.22 \mathrm{E}+08 & 9.75 \mathrm{E}+06 & 2.31 \mathrm{E}-02 & 4.30 \mathrm{E}-01 & 57.03 \% & \\ { }^{44} \mathrm{Ca} & 1.77 \mathrm{E}+11 & 8.70 \mathrm{E}+09 & 4.93 \mathrm{E}-02 & 9.16 \mathrm{E}-01 & 8.43 \% & \\ { }^{42} \mathrm{~K} & 2.33 \mathrm{E}+10 & 1.18 \mathrm{E}+09 & 5.04 \mathrm{E}-02 & 9.37 \mathrm{E}-01 & 6.32 \% & 1.18 \mathrm{E}+03 \\ { }^{45} \mathrm{Ca} & 2.78 \mathrm{E}+10 & 1.41 \mathrm{E}+09 & 5.05 \mathrm{E}-02 & 9.39 \mathrm{E}-01 & 6.12 \% & 2.34 \mathrm{E}+02 \\ { }^{44 \mathrm{~m}} \mathrm{Sc} & 4.01 \mathrm{E}+10 & 2.10 \mathrm{E}+09 & 5.22 \mathrm{E}-01 & 9.71 \mathrm{E}+00 & 2.95 \% & 8.38 \mathrm{E}+02 \\ { }^{44} \mathrm{Sc} & 9.50 \mathrm{E}+10 & 5.00 \mathrm{E}+09 & 5.26 \mathrm{E}-02 & 9.78 \mathrm{E}-01 & 2.23 \% & 5.00 \mathrm{E}+03\end{array}$

Table 2

Reaction signal for loaded ${ }^{191,193} \mathrm{Ir}$.

$\begin{array}{ccccccc}\text { Isotope } & 1.1 \mathrm{MJ} & 61 \mathrm{~kJ} & 61 \mathrm{~kJ} / 1.1 \mathrm{MJ} & \text { atoms/yield } & \text { Signal } & \mathrm{kJ} / \mathrm{MNA} \\ { }_{\text {nat }} \mathrm{Ir} & 2.58 \mathrm{E}+13 & 2.58 \mathrm{E}+13 & 1.00 \mathrm{E}+00 & 1.80 \mathrm{E}+01 & 1703.28 \% & \\ { }^{194} \mathrm{Ir} & 1.49 \mathrm{E}+08 & 2.12 \mathrm{E}+07 & 1.42 \mathrm{E}-01 & 2.57 \mathrm{E}+00 & 156.57 \% & 2.12 \mathrm{E}+01 \\ { }^{194 \mathrm{~m}} \mathrm{Ir} & 3.44 \mathrm{E}+07 & 4.41 \mathrm{E}+06 & 1.28 \mathrm{E}-01 & 2.31 \mathrm{E}+00 & 131.18 \% & 8.82 \mathrm{E}-01 \\ { }^{189} \mathrm{Ir} & 2.04 \mathrm{E}+07 & 1.50 \mathrm{E}+05 & 7.35 \mathrm{E}-03 & 1.33 \mathrm{E}-01 & 86.74 \% & 2.50 \mathrm{E}-02 \\ { }^{190} \mathrm{Ir} & 1.81 \mathrm{E}+10 & 8.26 \mathrm{E}+08 & 4.56 \mathrm{E}-02 & 8.23 \mathrm{E}-01 & 17.71 \% & 4.13 \mathrm{E}+02 \\ { }^{192} \mathrm{Ir} & 2.88 \mathrm{E}+10 & 1.33 \mathrm{E}+09 & 4.62 \mathrm{E}-02 & 8.33 \mathrm{E}-01 & 16.72 \% & 4.43 \mathrm{E}+02 \\ { }^{193 \mathrm{~m}} \mathrm{Ir} & 4.58 \mathrm{E}+09 & 2.48 \mathrm{E}+08 & 5.41 \mathrm{E}-02 & 9.76 \mathrm{E}-01 & 2.36 \% & 4.13 \mathrm{E}+01\end{array}$

$* \mathrm{MNA}=$ Minimum Number of Atoms required for a 5\% uncertainty.

The isotopes highlighted in blue are the loaded isotopes and the signal is just the difference in yields for the two cases. It should be noted that fewer atoms of the higher $\mathrm{Z}$ element Ir are tolerable in the capsule. Several clear signatures are observable by comparing the nominal $1 \mathrm{MJ}$ calculation with the $\mathrm{P}_{6}$ failure calculations. Perhaps the strongest signal is the $(\mathrm{n}, \gamma)$ capture products for both Sc and Ir which change a whopping $131 \%$ (157\%) for Sc (Ir), respectively, over the yield change. These values indicate that the neutron spectrum in the energies below $14 \mathrm{MeV}$ and the position and $\rho \mathrm{R}$ of the shell varied significantly between the $1 \mathrm{MJ}$ and failure cases. In addition, the $(n, 2 n)$ products indicated a difference - more so in the Ir case (17.7\%) than the Sc case $(2.2 \%)$ - because the threshold for the reaction is lower for $\operatorname{Ir}(8 \mathrm{MeV})$ than $\mathrm{Sc}(12 \mathrm{MeV})$, suggesting a 
marked difference in the neutron spectrum in the $8-12 \mathrm{MeV}$ range between the two simulations.

These radiochemical signatures are measurable with sufficient sample collection efficiency. The last column in tables 1 and 2 indicate the inverse of the collection efficiency required to make a 5\% measurement of a particular radionuclide (based on assumptions discussed below). For example, for the 50kJ failure, one would need a 53\% collection efficiency to make a $5 \%$ precision measurement of the neutron capture product ${ }^{46} \mathrm{Sc}$. Thus, the radionuclide with the largest signal may not be the best choice for an observable diagnostic.

It should be noted that this preliminary study has concentrated upon the sensitivity of one specific asymmetric mode and that eventually other modes can be investigated to map out the radiochemical signatures for others (like $\mathrm{P}_{4}, \mathrm{P}_{2}$, etc.). Although this asymmetric failure mode diagnostic did not require spatial loading of Sc or Ir (and when Ir was loaded in both polar and equatorial distributions it did not show a radiochemical signature that differed from uniform loading), other asymmetric failure modes might.

The number of radioactive nuclei collected from a NIF shot is highly sensitive to the number and position of the implanted tracer, the efficiency of the collection mechanism (including any chemical processing required), and the sensitivity of the decay counting apparatus. However, many of these sensitivities can be removed through the use of ratios of reaction products rather than absolute number reaction product counts. Consider the ratios of reaction products presented in Table 3 for both test cases. These ratios are insensitive to the total number of tracer nuclei implanted and, since they are all for the same radioactive element, to any chemical or physical fractionation resulting from the collection process.

Table 3

Select ratios of reaction products for neutron-induced reactions on ${ }^{45} \mathrm{Sc}$ and ${ }^{\text {nat }} \mathrm{Ir}$ for the two test cases (50 kJ and 1.1 MJ yields). Statistical uncertainties assuming the efficiencies listed above are shown only for the $50 \mathrm{~kJ}$ case since the corresponding values for the $1.1 \mathrm{MJ}$ shot are considerably smaller.

\begin{tabular}{|c|c|c|c|}
\hline Ratio & $\mathbf{5 0} \mathbf{~ k J}$ & $\mathbf{1 . 1} \mathbf{M J}$ & $\Delta_{\text {stat }}(\mathbf{5 0} \mathbf{~ k J})$ \\
\hline${ }^{46} \mathrm{Sc} /{ }^{44} \mathrm{Sc}$ & $1.51 \mathrm{E}-02$ & $6.37 \mathrm{E}-03$ & $4.32 \mathrm{E}-04$ \\
\hline${ }^{194} \mathrm{Ir} /{ }^{192} \mathrm{Ir}$ & $1.59 \mathrm{E}-02$ & $5.17 \mathrm{E}-03$ & $3.67 \mathrm{E}-05$ \\
\hline${ }^{194} \mathrm{Ir} /{ }^{190} \mathrm{Ir}$ & $2.57 \mathrm{E}-02$ & $8.23 \mathrm{E}-03$ & $5.73 \mathrm{E}-05$ \\
\hline${ }^{189} \mathrm{Ir} /{ }^{192} \mathrm{Ir}$ & $1.13 \mathrm{E}-04$ & $7.08 \mathrm{E}-04$ & $5.77 \mathrm{E}-06$ \\
\hline${ }^{194 \mathrm{~m}} \mathrm{Ir} /{ }^{192} \mathrm{Ir}$ & $3.32 \mathrm{E}-03$ & $1.19 \mathrm{E}-03$ & $5.83 \mathrm{E}-05$ \\
\hline
\end{tabular}

The uncertainties in these ratios depend on the collection process. Shorter half-lives and higher efficiency collection and decay counting procedures will decrease the uncertainty. 
The following assumptions were made for the collection and counting efficiency:

- $0.1 \%$ total collection efficiency

- 2 hour collection/chemical separation/sample loading time

- $20 \%$ photopeak decay counting efficiency (two "Clover Ge" detectors at 3")

- $50 \%$ chemical separation efficiency

- A counting interval of "half-of-a-half-life" for species $t_{1 / 2}<1$ week

- A counting interval of 4 days for species $t_{1 / 2}>1$ week

Figure 6 below shows the values of these ratios. The error bars shown are statistical uncertainties only. Sources of systematic uncertainties (and their likely values) include efficiency calibration of the counting facility $(1-2 \%)$; cross section data, particularly for higher energy $(\mathrm{n}, \gamma)$ reactions $(3-15 \%)$; and nuclear decay data $(<1 \%)$.

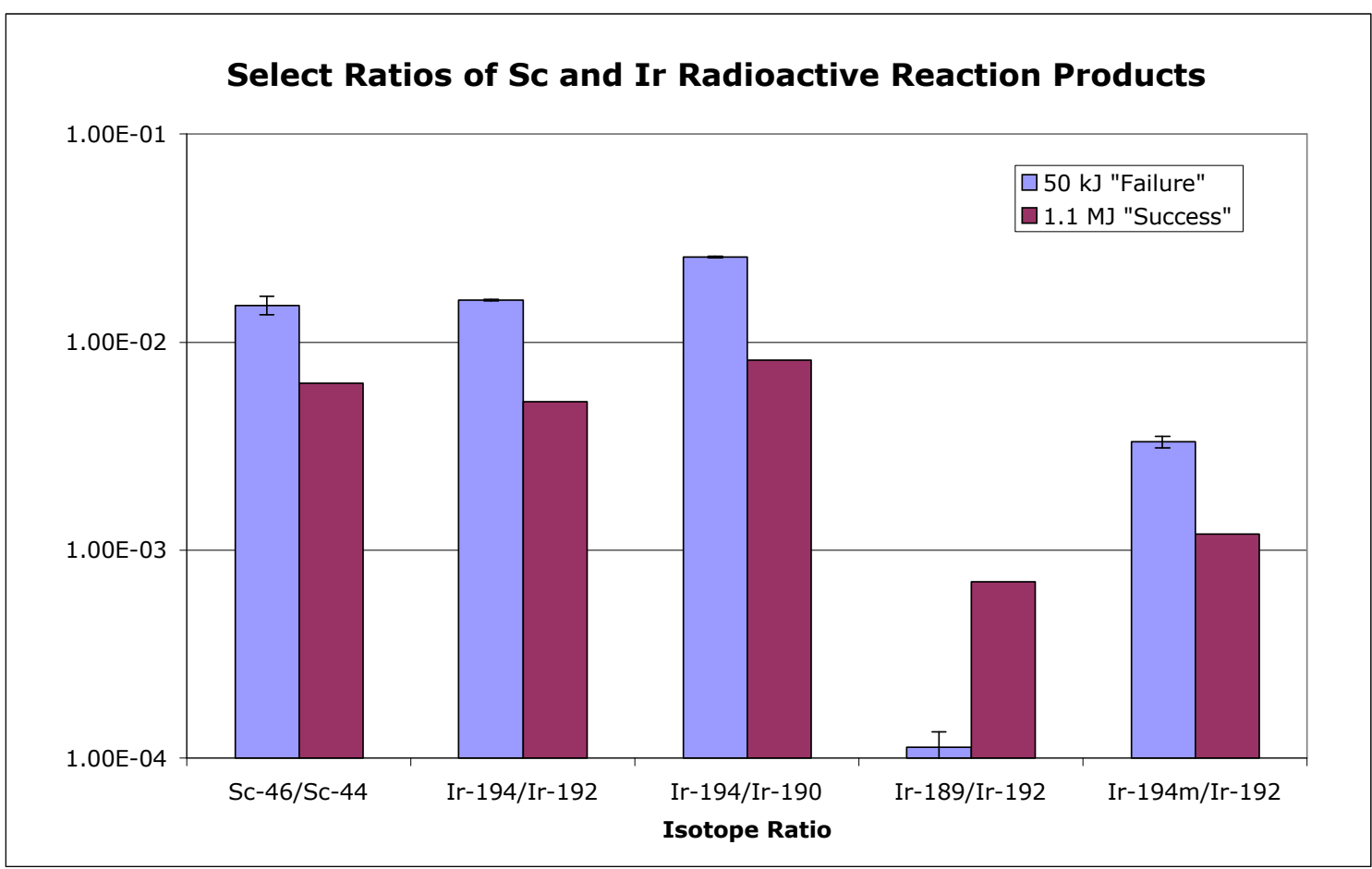

Figure 6. Reaction product ratios presented in Table 3. The error bars reflect statistical uncertainties only.

Finally, a preliminary estimate of a potential mix diagnostic was evaluated using the ${ }^{18} \mathrm{O}(\alpha, \mathrm{n})^{21} \mathrm{Ne}$ reaction. Realistic high mode surface imperfections were imposed upon the exterior of the ablation shell that were large enough to introduce some material mixing into the fuel but did not prevent robust burn. In these simulations $1.78 \times 10^{16}$ atoms of ${ }^{18} \mathrm{O}$ were loaded in the innermost part of the ablator. Table 4 contains the results of this evaluation. 
Table 4

Radiochemical mix diagnostic test.

$\begin{array}{cc}\text { Isotope } & \text { atoms } \\ { }^{16} \mathrm{O} & 3.04 \mathrm{E}+09 \\ { }^{17} \mathrm{O} & 3.04 \mathrm{E}+12 \\ { }^{18} \mathrm{O} & 2.67 \mathrm{E}+15 \\ { }^{20} \mathrm{Ne} & 3.46 \mathrm{E}+08 \\ { }^{21} \mathrm{Ne} & 5.26 \mathrm{E}+11 \\ { }^{22} \mathrm{Ne} & 8.68 \mathrm{E}+04 \\ \text { Isotope } & \\ \text { Ratio } & \text { Ratio } \\ { }^{21} \mathrm{Ne} /{ }^{18} \mathrm{O} & 1.97 \mathrm{E}-04 \\ { }^{17} \mathrm{O} /{ }^{21} \mathrm{Ne} & 1.73 \mathrm{E}-01\end{array}$

The ratio of ${ }^{21} \mathrm{Ne} /{ }^{18} \mathrm{O}$ is proportional to the amount of mix. Additional calculations for a clean case (no mix) and a 50\% more mix case are in progress. It should also be noted that the ${ }^{17} \mathrm{O} /{ }^{21} \mathrm{Ne}$ ratio provides information on $\mathrm{dE} / \mathrm{dx}$ of the $\alpha$-particles in comparison to the more penetrating $14 \mathrm{MeV}$ neutrons since the ${ }^{17} \mathrm{O}$ is produced from $(\mathrm{n}, 2 \mathrm{n})$ reactions. Calculations on the fuel $\rho \mathrm{R}$ and mix produced by deuteron/proton induced charged particle reactions are also in progress.

\section{Discussion}

In this initial assessment of the utility of advanced radiochemical diagnostics to failing point-design capsules, a methodology has been developed to consider more sophisticated probes of the implosion conditions. This report includes calculations that support the following claims. First, a clear and measurable radiochemical signature exists for one asymmetric failure mode $\left(\mathrm{P}_{6}\right)$; second, a possible signature for mix seems feasible; third, a possible signature for the energy loss over distance, $\mathrm{dE} / \mathrm{dx}$, of alpha particles appears to be measurable. This preliminary report has only touched upon a few of the many unresolved issues facing radiochemical diagnostic techniques. For example, in order to measure these signatures and extract quantitative failure mode information, both radiochemical gas sampling and solid sampling systems must be designed for the NIF target chamber, capsule doping schemes must be developed, and more calculations will be required to establish the radiochemical signatures for different asymmetric modes, including coupled asymmetric and mix failure modes.

Future efforts will be devoted to determining the sensitivity of selective nonuniformly doped materials to an asymmetric capsule environment, potentially tracking failure modes that are difficult to distinguish by any other diagnostic approach. The possible determination of mix effects and charged particle interaction ranges under imploding capsule plasma conditions will also be investigated by comparing the ${ }^{18} \mathrm{O}(\alpha, \mathrm{n}){ }^{21} \mathrm{Ne}$ and ${ }^{18} \mathrm{O}(\mathrm{n}, 2 \mathrm{n}){ }^{17} \mathrm{O}$ reactions. 